\title{
Long-term exposure to elemental constituents of particulate matter and cardiovascular mortality in 19 European cohorts: Results from the ESCAPE and TRANSPHORM projects
}

Meng Wang ${ }^{\mathrm{a}, *}$, Rob Beelen ${ }^{\mathrm{a}}$, Massimo Stafoggia ${ }^{\mathrm{b}}$, Ole Raaschou-Nielsen ${ }^{\mathrm{c}}$, Zorana Jovanovic Andersen ${ }^{\mathrm{c}, \mathrm{d}}$, Barbara Hoffmann ${ }^{\text {e,f }}$, Paul Fischer ${ }^{\mathrm{g}}$, Danny Houthuijs ${ }^{\mathrm{g}}$, Mark Nieuwenhuijsen ${ }^{\mathrm{h}, \mathrm{i}}$, Gudrun Weinmayr ${ }^{\mathrm{f}, \mathrm{j}}$, Paolo Vineis ${ }^{\mathrm{k}}$, Wei W. Xun ${ }^{\mathrm{k}, \mathrm{l}}$, Konstantina Dimakopoulou ${ }^{\mathrm{m}}$, Evangelia Samoli ${ }^{\mathrm{m}}$, Tiina Laatikainen ${ }^{\mathrm{n}, \mathrm{o}}$, Timo Lanki $^{\mathrm{n}}$, Anu W. Turunen ${ }^{\mathrm{n}}$, Bente Oftedal ${ }^{\mathrm{p}}$, Per Schwarze ${ }^{\mathrm{p}}$, Geir Aamodt ${ }^{\mathrm{p}}$, Johanna Penell ${ }^{\mathrm{q}}$, Ulf De Faire ${ }^{\mathrm{q}}$, Michal Korek ${ }^{\mathrm{q}}$, Karin Leander ${ }^{\mathrm{q}}$, Göran Pershagen ${ }^{\mathrm{q}}$, Nancy L. Pedersen ${ }^{\mathrm{r}}$, Claes-Göran Östenson ${ }^{\mathrm{s}}$, Laura Fratiglioni ${ }^{\mathrm{t}}$, Kirsten Thorup Eriksen ${ }^{\mathrm{c}}$, Mette Sørensen ${ }^{\mathrm{c}}$, Anne Tjønneland ${ }^{\mathrm{c}}$, Bas Bueno-de-Mesquita ${ }^{\mathrm{g}, \mathrm{u}}$, Marloes Eeftens ${ }^{\mathrm{a}, \mathrm{v}, \mathrm{w}}$, Michiel L. Bots ${ }^{\mathrm{x}}$, Kees Meliefste ${ }^{\mathrm{a}}$, Ursula Krämer ${ }^{\mathrm{e}}$, Joachim Heinrich ${ }^{\mathrm{y}}$, Dorothea Sugiri ${ }^{\mathrm{e}}$, Timothy Key ${ }^{z}$, Kees de Hoogh ${ }^{\text {aa }}$, Kathrin Wolf ${ }^{a b}$, Annette Peters ${ }^{\text {ab }}$, Josef Cyrys ${ }^{\text {ab,ac }}$, Andrea Jaensch ${ }^{j}$, Hans Concin ${ }^{\text {ad }}$, Gabriele Nagel ${ }^{\mathrm{j}, a d}$, Ming-Yi Tsai ${ }^{\mathrm{v}, \mathrm{w}}$, Harish Phuleria ${ }^{\mathrm{v}, \mathrm{w}}$, Alex Ineichen ${ }^{\mathrm{v}, \mathrm{w}}$, Nino Künzli ${ }^{\mathrm{v}, \mathrm{w}}$, Nicole Probst-Hensch ${ }^{\mathrm{v}, \mathrm{w}}$, Emmanuel Schaffner ${ }^{\mathrm{v}, \mathrm{w}}$, Alice Vilier ${ }^{\mathrm{ae}, \mathrm{af}, \mathrm{ag}}$, Françoise Clavel-Chapelon ${ }^{\text {ae,af,ag }}$, Christophe Declerq $^{\text {ah }}$, Fulvio Ricceri ${ }^{\text {ai }}$, Carlotta Sacerdote ${ }^{\text {aj }}$, Alessandro Marcon ${ }^{\text {ak }}$, Claudia Galassi ${ }^{\text {aj }}$, Enrica Migliore ${ }^{\text {aj }}$, Andrea Ranzi ${ }^{\text {al }}$, Giulia Cesaroni ${ }^{\mathrm{b}}$, Chiara Badaloni ${ }^{\mathrm{b}}$, Francesco Forastiere ${ }^{\mathrm{b}}$, Michail Katsoulis ${ }^{\mathrm{am}}$, Antonia Trichopoulou ${ }^{\mathrm{am}}$, Menno Keuken ${ }^{\mathrm{an}}$, Aleksandra Jedynska ${ }^{\text {an }}$, Ingeborg M. Kooter ${ }^{\text {an }}$, Jaakko Kukkonen ${ }^{\text {ao }}$, Ranjeet S. Sokhi ${ }^{\text {ap }}$, Bert Brunekreef ${ }^{\mathrm{a}, \mathrm{x}}$, Klea Katsouyanni ${ }^{\mathrm{m}}$, Gerard Hoek ${ }^{\mathrm{a}}$

a Institute for Risk Assessment Sciences, Utrecht University, Utrecht, The Netherlands

b Department of Epidemiology, Lazio Regional Health Service, Rome, Italy

' Danish Cancer Society Research Center, Copenhagen, Denmark

d Center for Epidemiology and Screening, Department of Public Health, University of Copenhagen, Copenhagen, Denmark

e IUF, Leibniz Research Institute for Environmental Medicine, Düsseldorf, Germany

${ }^{\mathrm{f}}$ University of Düsseldorf, Düsseldorf, Germany

${ }^{g}$ National Institute of Public Health and the Environment, Bilthoven, The Netherlands

${ }^{\text {h }}$ Centre for Research in Environmental Epidemiology (CREAL), Barcelona, Spain

i Consortium for Biomedical Research in Epidemiology and Public Health (CIBER en Epidemiología y Salud Pública - CIBERESP), Madrid, Spain

j Institute of Epidemiology and Medical Biometry, Ulm University, Ulm, Germany

${ }^{\mathrm{k}}$ MRC-HPA Centre for Environment and Health, Department of Epidemiology and Biostatistics, Imperial College London, London, United Kingdom

${ }^{1}$ University College London, London, United Kingdom

m Department of Hygiene, Epidemiology and Medical Statistics, Medical School, University of Athens, Athens, Greece

${ }^{n}$ National Institute for Health and Welfare, Kuopio, Finland

${ }^{\circ}$ Institute of Public Health and Clinical Nutrition, University of Eastern Finland, Kuopio, Finland

p Norwegian Institute of Public Health, Oslo, Norway

${ }^{\mathrm{q}}$ Institute of Environmental Medicine, Karolinska Institutet, Stockholm, Sweden

${ }^{\mathrm{r}}$ Department of Medical Epidemiology and Biostatistics, Karolinska Institutet, Stockholm, Sweden

s Department of Molecular Medicine and Surgery, Karolinska Institutet, Stockholm, Sweden

${ }^{\mathrm{t}}$ Aging Research Center, Department of Neurobiology, Care Sciences and Society, Karolinska Institutet, Stockholm, Sweden

u School of Public Health, Imperial College London, London, United Kingdom

$\checkmark$ Swiss Tropical and Public Health Institute, Basel, Switzerland

w University of Basel, Basel, Switzerland

${ }^{x}$ Julius Center for Health Sciences and Primary Care, University Medical Center Utrecht, Utrecht, The Netherlands

${ }^{y}$ Institute of Epidemiology I, Helmholtz Zentrum München, German Research Center of Environmental Health, Neuherberg, Germany

${ }^{z}$ Cancer Epidemiology Unit, Nuffield Department of Clinical Medicine, University of Oxford, Oxford, United Kingdom

aa MRC-PHE Centre for Environment and Health, Department of Epidemiology and Biostatistics, Imperial College London, London, United Kingdom

${ }^{\mathrm{ab}}$ Institute of Epidemiology II, Helmholtz Zentrum München, German Research Center for Environmental Health, Neuherberg, Germany

Abbreviations: BMI, body mass index; CTS, California Teachers Study; Cu, copper; CVD, cardiovascular disease; ESCAPE, European Study of Cohorts for Air Pollution Effects; Fe, iron;

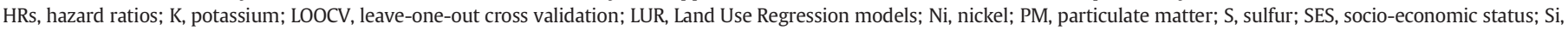

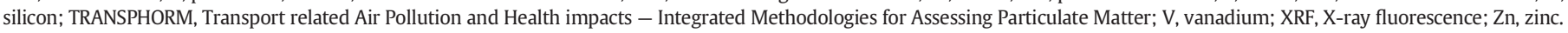

* Corresponding author at: Institute for Risk Assessment Sciences, Division Environmental Epidemiology, Utrecht University, P.O. Box 80178, 3508 TD Utrecht, The Netherlands.

Tel.: + 316 16697117; fax: +31302539499.

E-mail address: M.Wang@uu.nl (M. Wang). 
ac University of Augsburg, Environmental Science Center, Augsburg, Germany

${ }^{\text {ad }}$ Agency for Preventive and Social Medicine, Bregenz, Austria

ae Inserm, Centre for Research in Epidemiology and Population Health (CESP), U1018, Nutrition, Hormones and Women's Health Team, Villejuif, France

af University Paris Sud, UMRS 1018, Villejuif, France

ag IGR, Villejuif, France

ah French Institute for Public Health Surveillance (InVS) 12, Saint-Maurice, France

ai Human Genetics Foundation - HuGeF, Turin, Italy

aj Unit of Cancer Epidemiology, AO Citta' della Salute e della Scienza, University of Turin and Center for Cancer Prevention, Turin, Italy

ak Unit of Epidemiology \&' Medical Statistics, Department of Public Health and Community Medicine, University of Verona, Italy

${ }^{\text {al }}$ Environmental Health Reference Centre, Regional Agency for Environmental Prevention of Emilia-Romagna, Modena, Italy

am Hellenic Health Foundation, Athens, Greece

an TNO, Netherlands Organisation for Applied Scientific Research, Utrecht, The Netherlands

ao Finnish Meteorological Institute, Helsinki, Finland

ap University of Hertfordshire College Lane, Hatfield, United Kingdom

\section{A R T I C L E I N F O}

\section{Article history:}

Received 4 November 2013

Accepted 27 January 2014

Available online 18 February 2014

\section{Keywords:}

Long-term exposure

Particulate matter

Constituents

Cardiovascular mortality

ESCAPE

TRANSPHORM

\begin{abstract}
A B S T R A C T
Background: Associations between long-term exposure to ambient particulate matter (PM) and cardiovascular (CVD) mortality have been widely recognized. However, health effects of long-term exposure to constituents of PM on total CVD mortality have been explored in a single study only.

Aims: The aim of this study was to examine the association of PM composition with cardiovascular mortality. Methods: We used data from 19 European ongoing cohorts within the framework of the ESCAPE (European Study of Cohorts for Air Pollution Effects) and TRANSPHORM (Transport related Air Pollution and Health impacts - Integrated Methodologies for Assessing Particulate Matter) projects. Residential annual average exposure to elemental constituents within particle matter smaller than 2.5 and $10 \mu \mathrm{m}\left(\mathrm{PM}_{2.5}\right.$ and $\left.\mathrm{PM}_{10}\right)$ was estimated using Land Use Regression models. Eight elements representing major sources were selected a priori (copper, iron, potassium, nickel, sulfur, silicon, vanadium and zinc). Cohort-specific analyses were conducted using Cox proportional hazards models with a standardized protocol. Random-effects metaanalysis was used to calculate combined effect estimates.

Results: The total population consisted of 322,291 participants, with 9545 CVD deaths. We found no statistically significant associations between any of the elemental constituents in $\mathrm{PM}_{2.5}$ or $\mathrm{PM}_{10}$ and CVD mortality in the pooled analysis. Most of the hazard ratios (HRs) were close to unity, e.g. for $\mathrm{PM}_{10}$ Fe the combined HR was 0.96 (0.84-1.09). Elevated combined $\mathrm{HRs}$ were found for $\mathrm{PM}_{2.5} \mathrm{Si}$ (1.17, 95\% CI: 0.93-1.47), and $\mathrm{S}$ in $\mathrm{PM}_{2.5}$ (1.08, 95\% CI: 0.95-1.22) and $\mathrm{PM}_{10}(1.09,95 \%$ CI: 0.90-1.32).

Conclusion: In a joint analysis of 19 European cohorts, we found no statistically significant association between long-term exposure to 8 elemental constituents of particles and total cardiovascular mortality.
\end{abstract}

(c) 2014 Elsevier Ltd. All rights reserved.

\section{Introduction}

Recent studies of health effects of particulate matter (PM) show accumulating evidence of adverse effects on cardiovascular (CVD) mortality (Brook et al., 2010; Hoek et al., 2013). However, effect estimates of long-term exposure to $\mathrm{PM}_{2.5}$ and $\mathrm{PM}_{10}$ (particles $<2.5 \mu \mathrm{m}$ and $10 \mu \mathrm{m}$ in aerodynamic diameter) varied among different studies and geographical locations, showing elevated risks in some cities and areas in Europe and the United States (Cesaroni et al., 2013; Laden et al., 2006; Lepeule et al., 2012; Lipsett et al., 2011; Pope et al., 2002) but no or little association in others (Beelen et al., 2008; Puett et al., 2011).

Ambient $\mathrm{PM}_{2.5}$ and $\mathrm{PM}_{10}$ represent a heterogeneous mixture of constituents from diverse sources e.g. fossil fuel combustion, biomass burning and human activity (Kelly and Fussell, 2012). However, little is known about which PM constituents are associated with higher risks. Several studies showed evidence of acute effects of PM components on CVD mortality, but results varied among studies (Cao et al., 2012; Ito et al., 2011; Valdes et al., 2012; Zhou et al., 2011). In the large national study of United States, only nickel $(\mathrm{Ni})$ and vanadium $(\mathrm{V})$ were associated with CVD mortality (Bell et al., 2009). The reasons for these differences are not clear but may include methodological differences, chance findings as well as true variations related to PM composition and/or population susceptibility. Long-term effects of specific elemental components on CVD mortality have only been examined by a single study in the U.S. which suggested that cardiopulmonary mortality was associated significantly with $\mathrm{PM}_{2.5}$ (HR: $1.11,95 \% \mathrm{CI}$ : 1.03-1.21), sulfate (HR: $1.14,95 \%$ CI: 1.01-1.29), nitrate (HR: $1.11,95 \% \mathrm{CI}: 1.03-1.19)$ and silicon (HR: 1.05, 95\% CI: 1.00-1.10) (Ostro et al., 2010, 2011). Toxicological studies have identified several transition metals (copper, iron, vanadium, nickel, and zinc) that are likely to promote inflammation and oxidative stress (Gerlofs-Nijland et al., 2007; Happo et al., 2008, 2010).

A recent study within ESCAPE (European Study of Cohorts for Air Pollution Effects) reported overall no statistically significant associations between long-term exposure to PM mass $\left(\mathrm{PM}_{2.5}, \mathrm{PM}_{10}\right)$ and cardiovascular mortality averaged over 19 ongoing cohorts in Europe (Beelen et al., accepted for publication). The magnitude of the association differed across cohorts and we hypothesized that some of the difference in effect estimates could be due to well-documented differences in particle composition in the study areas (De Hoogh et al., 2013). De Hoogh et al. (2013) documented that the correlation between particle mass and several elements was moderate to low, suggesting that the null effect for PM mass may hide effects for some components. Furthermore for some elements (e.g. $\mathrm{V}$ and $\mathrm{Ni}$ ) the major source (shipping, residual oil combustion) was present only in a few of the study areas. Therefore, more specific examinations are needed taking individual particle components into account.

The aim of this paper was to investigate effects of long term exposure to PM constituents on CVD mortality within the ESCAPE (European Study of Cohorts for Air Pollution Effects) and TRANSPHORM (Transport related Air Pollution and Health impacts - Integrated Methodologies for Assessing Particulate Matter) projects. Standardized methods for exposure assessment, confounder and endpoint definition and statistical analysis were applied to 19 ongoing cohort studies.

\section{Methods}

The association between PM constituents and cardiovascular mortality was analyzed in each cohort separately using a common statistical 
Table 1

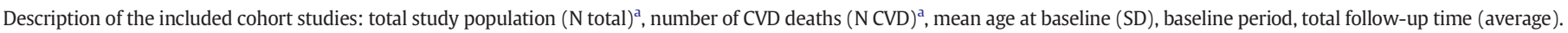
Order of studies is north to south.

\begin{tabular}{|c|c|c|c|c|c|c|}
\hline Cohort & Study area description & $\mathrm{N}$ total & $\mathrm{NCVD}^{\mathrm{b}}$ & $\begin{array}{l}\text { Age } \\
\text { (years) }\end{array}$ & Baseline period & $\begin{array}{l}\text { Follow-up time } \\
\text { (person years) }\end{array}$ \\
\hline FINRISK, Finland & Greater Helsinki Area and Turku City and its rural surroundings & 10,224 & 225 & $47.9(13.2)$ & $1992 ; 1997 ; 2002 ; 2007$ & $108,434(10.6)$ \\
\hline HUBRO, Norway & City of Oslo & 18,234 & 332 & $48.3(15.2)$ & 2000-2001 & $175,076(9.6)$ \\
\hline SNAC-K, Sweden & City of Stockholm & 2401 & 140 & $70.3(8.1)$ & 2001-2004 & $15,568(6.5)$ \\
\hline SALT/Twin gene, Sweden & Stockholm County & 5473 & 206 & $58.0(9.9)$ & $1998-2002$ & $47,767(8.7)$ \\
\hline 60 y olds, Sweden & Stockholm County & 3612 & 81 & $60.4(0.1)$ & 1997-1999 & $40,612(11.2)$ \\
\hline SDPP, Sweden & Stockholm County & 7408 & 55 & $47.1(5.0)$ & 1992-1998 & $102,831(13.9)$ \\
\hline DCH, Denmark & City of Copenhagen and surrounding areas & 35,458 & 678 & $56.7(4.4)$ & 1993-1997 & $469,571(13.2)$ \\
\hline EPIC-MORGEN, Netherlands & $\begin{array}{l}\text { Cities of Amsterdam, Maastricht and } \\
\text { Doetinchem and surrounding rural areas }\end{array}$ & 16,446 & 185 & $43.9(10.9)$ & 1993-1997 & $217,722(13.2)$ \\
\hline EPIC-PROSPECT, Netherlands & City of Utrecht and surrounding rural areas & 15,670 & 290 & $57.7(6.0)$ & 1993-1997 & $202,809(12.9)$ \\
\hline SALIA, Germany & $\begin{array}{l}\text { Areas in the cities of Dortmund, Duisburg, Essen, } \\
\text { Gelsenkirchen and Herne situated in the Ruhr } \\
\text { area and adjacent towns Borken and Dülmen }\end{array}$ & 4352 & 206 & $54.5(0.6)$ & 1985-1987; 1990-1994 & $81,093(18.6)$ \\
\hline EPIC-Oxford, UK & $\begin{array}{l}\text { Urban and rural areas within } 400 \mathrm{~km} \\
\text { around London-Oxford area }\end{array}$ & 38,941 & 661 & $45.8(13.7)$ & $1993-2001$ & $491,542(12.6)$ \\
\hline KORA, Germany & City of Augsburg and two adjacent rural counties & 8399 & 270 & $49.5(13.8)$ & 1994-1995; 1999-2001 & $88,592(10.5)$ \\
\hline VHM\&PP, Austria & $\begin{array}{l}\text { State of Vorarlberg, excluding high mountain areas } \\
(>600 \mathrm{~m}) \text { and areas within } 300 \mathrm{~m} \text { of state border }\end{array}$ & 117,824 & 5858 & $41.9(14.9)$ & 1985-2005 & $2,039,328(17.3)$ \\
\hline SAPALDIA, Switzerland & City of Lugano & 1250 & 14 & $42.0(11.9)$ & 1991 & $20,294(16.2)$ \\
\hline E3N, France & $\begin{array}{l}\text { Cities of Paris, Grenoble, Lyon and Marseille } \\
\text { and surrounding rural areas }\end{array}$ & 10,915 & 89 & $53.0(6.7)$ & 1993-1996 & $147,021(13.5)$ \\
\hline EPIC-Turin, Italy & City of Turin & 7261 & 46 & $50.4(7.5)$ & 1993-1998 & $97,549(13.4)$ \\
\hline SIDRIA-Turin, Italy & City of Turin & 5054 & 29 & $44.2(6.2)$ & 1999 & $55,667(11.0)$ \\
\hline SIDRIA-Rome, Italy & City of Rome & 9177 & 64 & $44.3(6.0)$ & 1999 & $102,856(11.2)$ \\
\hline EPIC-Athens, Greece & Greater Athens area & 4192 & 116 & $49.4(11.7)$ & 1994-1999 & $46,852(11.2)$ \\
\hline
\end{tabular}

a Number of observations without missing value in any confounder variable of Model 3 (main model).

b $\mathrm{CVD}=$ all cardiovascular mortality.

protocol for exposure assessment, outcome definition, confounder models and statistical analysis. Methods followed the ESCAPE analysis protocol described in previous papers (Beelen et al., accepted for publication, in press; Raaschou-Nielsen et al., 2013). Cohort-specific results were evaluated and pooled using meta-analysis at the coordinating institute (IRAS, Utrecht University). Pooling of the cohort data was not possible due to data transfer and privacy issues.

\subsection{Study populations}

Our analysis included 19 cohorts from 12 countries where PM measurements were available from north to south Europe: Finland (FINRISK), Norway (HUBRO), Sweden (SNAC-K, SALT, 60 y olds, SDPP), Denmark (DCH), The Netherlands (EPIC-MORGEN, EPIC-PROSPECT), Germany (SALIA, KORA), the United Kingdom (EPIC-Oxford), Austria (VHM\&PP), Switzerland (SAPALDIA-Lugano), France (E3N), Italy (EPICTurin, SIDRIA-Turin, SIDRIA-Rome), and Greece (EPIC-Athens). Detailed information of the study design and the characteristics of each cohort are described in Appendix A. Key design characteristics are included in Table 1. All cohorts were samples from the general population. The study areas of most cohorts consisted of a large city and its surrounding area. Some of the cohorts included large regions of the country such as EPIC-MORGEN in The Netherlands and the VHM\&PP cohort in Vorarlberg, Austria. Table 2 summarizes population characteristics of the cohorts. All included cohort studies were approved by the institutional medical Ethics Committees and conducted in accordance with the Declaration of Helsinki, or had authorization from the data protection authority. All subjects provided informed consent or authorization from the data protection authority.

\subsection{Definition of cardiovascular mortality outcome}

In all cohorts, follow-up was based upon linkage to mortality registries with one exception in Athens where follow-up was active. All CVD mortality was defined on the basis of the underlying cause of death recorded on death certificates as ICD-9: 400-440; ICD-10: I10-I70.

\subsection{Exposure assessment}

Within ESCAPE, we a priori selected 8 elements (copper $(\mathrm{Cu})$, iron $(\mathrm{Fe})$, potassium $(\mathrm{K})$, nickel $(\mathrm{Ni})$, sulfur $(\mathrm{S})$, silicon $(\mathrm{Si})$, vanadium $(\mathrm{V})$ and zinc $(\mathrm{Zn})$ ), reflecting major anthropogenic sources such as road traffic non tailpipe emissions including brake linings ( $\mathrm{Cu}, \mathrm{Fe}, \mathrm{Zn}$ ) and tire wear (Zn), industrial (smelter) emissions ( $\mathrm{Fe}, \mathrm{Zn}$ ), crustal materials ( $\mathrm{Si}, \mathrm{K})$, fossil fuel combustion (Ni, V, S) and biomass burning (K). These elements were included because they reflected the major local particle sources, had evidences for toxicity and had a high percentage ( $>75 \%$ ) of welldetected samples. We restricted to eight key elements to limit false positive associations that could arise from analyzing all measured elements. Annual average elemental concentrations at the baseline residential addresses of study participants were estimated by Land Use Regression models (LUR) following a standardized procedure described previously (De Hoogh et al., 2013). Briefly, three two-week measurements of $\mathrm{PM}_{2.5}$ and $\mathrm{PM}_{10}$ were conducted during different seasons between October 2008 and May 2011 at 20 sites (except in The Netherlands 40 sites) in each cohort study area ( 1 year per study area). Annual average concentrations of PM constituents were obtained by adjusting temporal variation measured at continuous background sampling sites in each study area in the entire period (Eeftens et al., 2012). Teflon filters were weighed before and after each measurement centrally at IRAS, Utrecht University and were then sent to Cooper Environmental Services (Portland, OR, USA) to detect elemental composition. All filters were analyzed for elemental compositions using X-ray fluorescence (XRF). Details of the measurements, analyses and results have been published elsewhere (De Hoogh et al., 2013). Area-specific LUR models were developed for each element to explain annual concentrations. Models explained modest to large fractions of variation of PM constituents (mean model $\mathrm{R}^{2}$ : $0.43-$ 0.79 across constituents) (see Tables B.2-B.17 in Appendix B). Only 16 out of 224 models of the 14 study areas could not be built as there were no variables that explained concentration variability (De Hoogh et al., 2013) (see Table B.1 in Appendix B). To avoid extreme values of PM constituents at cohort addresses, we truncated the values of the predictor variables to the upper or lower limit of those at the measurement sites. 
Table 2

Population characteristics at baseline of the included cohort studies. Order of studies is north to south. Detailed description of each cohort can be found in Appendix C.

\begin{tabular}{|c|c|c|c|c|c|c|c|c|c|c|}
\hline Cohort & \% Women & $\begin{array}{l}\text { \% Never } \\
\text { smokers }\end{array}$ & Cigarettes/day ${ }^{\mathrm{a}}$ & $\begin{array}{l}\text { Years of } \\
\text { smoking }^{\mathrm{a}}\end{array}$ & $\begin{array}{l}\mathrm{BMI}^{\mathrm{a}} \\
\left(\mathrm{kg} / \mathrm{m}^{2}\right)\end{array}$ & Fruit intake $^{\mathrm{b}}$ & $\begin{array}{l}\text { Alcohol } \\
\text { intake }^{c}\end{array}$ & $\begin{array}{l}\text { \% Married/living } \\
\text { with partner }\end{array}$ & $\begin{array}{l}\text { \% Low } \\
\text { educational level }\end{array}$ & $\begin{array}{l}\text { \% (Self) } \\
\text { employed }\end{array}$ \\
\hline FINRISK, Finland & $53.8 \%$ & $45.4 \%$ & $3.8(7.8)$ & $8.6(12.2)$ & $26.4(4.6)$ & $66.3 \%$ & $0.9(1.3)$ & $70.1 \%$ & $31.0 \%$ & $69.2 \%$ \\
\hline HUBRO, Norway & $56.1 \%$ & $46.0 \%$ & $6.7(8.4)$ & $11.5(14.4)$ & $25.7(4.1)$ & $39.9 \%$ & $50.6 \%$ & $49.8 \%$ & $17.7 \%$ & NA \\
\hline SNAC-K, Sweden & $60.0 \%$ & $44.3 \%$ & $7.1(9.5)$ & $9.8(15.2)$ & $26.0(4.1)$ & NA & $21.8 \%$ & $54.2 \%$ & $21.2 \%$ & $28.6 \%$ \\
\hline SALT/Twin gene, Sweden & $55.7 \%$ & $38.7 \%$ & $8.5(9.7)$ & $16.7(17.3)$ & $28.6(4.1)$ & NA & NA & $68.0 \%$ & $21.5 \%$ & NA \\
\hline 60 y olds, Sweden & $52.5 \%$ & $41.0 \%$ & $8.0(9.1)$ & $15.2(16.4)$ & $26.8(4.2)$ & $64.2 \%$ & $8.9(9.7)$ & $71.6 \%$ & $27.5 \%$ & $51.4 \%$ \\
\hline SDPP, Sweden & $61.7 \%$ & $37.4 \%$ & $8.5(8.8)$ & $12.3(12.4)$ & $25.6(4.0)$ & $92.4 \%$ & $1.3(1.9)$ & $83.6 \%$ & $25.5 \%$ & $91.8 \%$ \\
\hline DCH, Denmark & $54.1 \%$ & $36.3 \%$ & $6.3(10.4)$ & $18.7(17.1)$ & $26.0(4.1)$ & $183.2(151.2)$ & $21.7(22.8)$ & $69.2 \%$ & $29.6 \%$ & $80.1 \%$ \\
\hline EPIC-MORGEN, Netherlands & $54.4 \%$ & $35.0 \%$ & $10.4(11.1)$ & $14.3(13.7)$ & $25.2(4.0)$ & $171.9(129.2)$ & $12.7(18.0)$ & $67.7 \%$ & $11.9 \%$ & NA \\
\hline EPIC-PROSPECT, Netherlands & $100 \%$ & $45.0 \%$ & $5.7(7.4)$ & $15.2(16.5)$ & $25.5(4.1)$ & $231.6(139.2)$ & $9.0(12.4)$ & $76.9 \%$ & $22.2 \%$ & NA \\
\hline SALIA, Germany & $100 \%$ & $74.5 \%$ & $2.6(6.6)$ & $4.4(10.5)$ & NA & NA & NA & NA & $28.8 \%$ & NA \\
\hline EPIC-Oxford, UK & $77.5 \%$ & $63.3 \%$ & $5.0(8.3)$ & $6.7(11.2)$ & $24.0(3.9)$ & $259.9(204.5)$ & $9.1(11.7)$ & $70.8 \%$ & $36.5 \%$ & $72.5 \%$ \\
\hline KORA, Germany & $50.8 \%$ & $43.7 \%$ & $9.2(13.3)$ & $12.0(14.2)$ & $27.2(4.6)$ & $59.5 \%$ & $16.3(22.3)$ & $75.7 \%$ & $12.6 \%$ & $58.3 \%$ \\
\hline VHM\&PP, Austria & $56.1 \%$ & $69.9 \%$ & NA & NA & $24.8(4.3)$ & NA & NA & $68.4 \%$ & NA & $69.3 \%$ \\
\hline SAPALDIA, Switzerland & $55.7 \%$ & $44.6 \%$ & $11.1(14.4)$ & $11.1(13.0)$ & $23.8(3.9)$ & NA & NA & $58.1 \%$ & $11.3 \%$ & $80.8 \%$ \\
\hline E3N, France & $100 \%$ & $49.3 \%$ & NA & NA & $22.8(3.2)$ & $242.0(164.7)$ & $12.0(15.1)$ & NA & $5.0 \%$ & NA \\
\hline EPIC-Turin, Italy & $47.7 \%$ & $42.6 \%$ & $7.2(8.2)$ & $17.6(16.3)$ & $25.3(3.8)$ & $318.2(182.2)$ & $18.1(20.3)$ & $85.6 \%$ & $43.6 \%$ & NA \\
\hline SIDRIA-Turin, Italy & $51.8 \%$ & $37.5 \%$ & $9.3(10.2)$ & $11.3(10.6)$ & NA & NA & NA & $95.4 \%$ & $17.5 \%$ & $72.2 \%$ \\
\hline SIDRIA-Rome, Italy & $52.8 \%$ & $34.6 \%$ & $10.1(10.5)$ & $11.7(10.4)$ & NA & NA & NA & $100 \%$ & $44.9 \%$ & NA \\
\hline EPIC-Athens, Greece & $55.0 \%$ & $39.5 \%$ & $1.7(15.0)$ & $10.8(13.1)$ & $27.5(4.5)$ & $402.6(258.2)$ & $9.2(14.5)$ & $78.0 \%$ & $23.6 \%$ & $66.9 \%$ \\
\hline
\end{tabular}

NA is not available.

a Mean (SD).

b Mean (SD) (g/day) or percentage with daily fruit consumption. For SDPP it is percentage daily/weekly fruit consumption.

c Mean (SD) (g/day) or percentage with daily alcohol consumption. For FINRISK it is number of glasses of alcoholic drink during last week. For SDPP it number of glasses of alcoholic drink per day. For HUBRO it is percentage with weekly alcohol consumption.

This procedure was previously applied for nitrogen oxides and $\mathrm{PM}_{10}$, $\mathrm{PM}_{2.5}$ and $\mathrm{PM}_{2.5}$ absorbance (Beelen et al., accepted for publication, in press) and has been shown to result in more realistic exposure estimates for these pollutants(Wang et al., 2012).

\subsection{Statistical analyses}

\subsubsection{Cohort specific analyses}

Standard Cox proportional hazards models were calculated for the cohort specific analyses, with age as the underlying time scale using a common protocol (Beelen et al., accepted for publication, in press). Censoring occurred at the time of death for non-CVD causes, migration out of the country leading to loss of follow-up, loss to follow-up for other reasons, or at end of follow-up, whichever came first. Air pollution exposure was analyzed as a linear time-invariant variable. Potential individual-level confounders were available from questionnaire data at baseline. A priori we specified three confounder models with increasing level of adjustment. Confounder models were decided based upon previous cohort studies of air pollution and mortality and availability of data in a majority of the cohorts. Model 1 included age (time axis), gender, and calendar time (year(s) of enrollment) only. Model 2 adjusted for additional individual level variables: smoking status (never/former/present), smoking intensity, smoking duration (years), environmental tobacco smoke, fruit intake, vegetables intake, alcohol consumption (linear and squared term), body mass index (BMI) (linear and squared term) $\left(\mathrm{kg} / \mathrm{m}^{2}\right)$, educational level (low, medium, high), occupational class (white/blue collar classification), employment status, and marital status. Model 3 further adjusted for area-level socio-economic status (SES) variables (mostly mean income of neighborhood or municipality). Model 3 was selected as the main confounder model. Only subjects with complete information for Model 3 variables were included in the analyses (see Tables C.1-C.19 in Appendix C).

As constituents from similar sources may be correlated with each other, we additionally conducted two-pollutant models for all elements, adjusting for all the standard pollutants $\left(\mathrm{NO}_{2}, \mathrm{NOx}, \mathrm{PM}_{2.5}, \mathrm{PM}_{10}, \mathrm{PM}_{2.5}\right.$ absorbance and coarse particles) and other elements separately. We restricted our two-pollutant models to the cohorts with Pearson correlations between LUR based estimates of the two pollutants lower than 0.7 to avoid multicollinearity (Dominici et al., 2010).
In sensitivity analyses, we added to Model 3 prevalent hypertension and physical activity, and as further classical cardiovascular risk factors: prevalent diabetes and cholesterol level. Extended confounder models were used in sensitivity analyses because some of the air pollution effect might be mediated (hypertension) or affected (physical activity) by these factors. We further evaluated the impact of inclusion of modeled road traffic noise to Model 3 because noise and air pollution have been shown to be correlated and may both affect CVD mortality. Noise was used as continuous variable and as categorical variable (5 dB categories) (Beelen et al., 2009).

We did not perform individual effect modification analyses for the constituents as none of the evaluated factors (age, sex, fruit intake, smoking status) was an effect modifier in the analysis of $\mathrm{PM}_{2.5}, \mathrm{PM}_{10}, \mathrm{PM}_{2.5}$ absorbance and $\mathrm{NO}_{2}$ and cardiovascular mortality in the same cohorts (Beelen et al., accepted for publication). As we did not observe significant associations with more specific cardiovascular diseases (stroke, ischemic heart disease) in our previous paper, we also refrained from analyzing the association of constituents and these causes.

\subsubsection{Meta-analysis}

Meta-analyses of cohort-specific estimates were conducted using the DerSimonian-Laird method with random effects (DerSimonian and Laird, 1986). Hazard ratios (HRs) and 95\% confidence intervals (CIs) were calculated for fixed increments. The increments for each constituent were selected assessing particle constituents by rounding the average difference between the 10th and 90th percentiles of annual average concentrations in all study areas. Heterogeneity between cohorts was quantified by the $\mathrm{I}^{2}$ statistic and tested by the $X^{2}$ test from Cochran's Q statistic (Higgins and Thompson, 2002).

We tested whether effect estimates differed by regions of ESCAPE (north: Sweden, Norway, Finland, Denmark; west and middle: the United Kingdom, The Netherlands, Germany, France, Austria, Switzerland; south: Italy and Greece) using stratified analysis and a regional indicator in the meta-regression.

In addition, we estimated combined effect estimates for cohorts with leave-one-out cross validation (LOOCV) $\mathrm{R}^{2}$ lower and higher than 0.5 for each element. In a sensitivity analysis we excluded cohorts with a weight larger than $50 \%$ in the meta-analysis. 
All cohort-specific analyses and meta-analyses were done in STATA, version 10-12 (StataCorp, College Station, TX, USA). We defined statistical significance as a p value $<0.05$.

\section{Results}

\subsection{Characteristics of the study population}

The entire study population consisted of 322,291 participants contributing 4,551,184 person years at risk (average time of follow-up 14.1 years), with 9545 CVD deaths during follow-up (Table 1). Cohorts were recruited mostly in the 1990s. Cohorts differed in the number of participants, the mean baseline age, and availability of data on confounders (Table 2 and Tables C.1-C.19 in Appendix C). Age gender, smoking status, and area-level SES were available for all cohorts. Smoking intensity and duration were available as continuous variables for all cohorts, except VHM\&PP and E3N. VHM\&PP had data on occupation and employment status, but not on education.

\subsection{Air pollution exposure}

Concentration distributions of estimated particle constituents varied substantially between and within study areas (Figs. 1 and 2). Cu, Fe and $\mathrm{Zn}$ (in $\mathrm{PM}_{2.5}$ and $\mathrm{PM}_{10}$ ) showed highest overall concentrations in southern Europe and high spatial contrasts in all study areas. Highest concentrations and contrasts of crustal elements ( $\mathrm{K}$ and $\mathrm{Si}$ ) were observed for cohorts in north and south Europe. Exposure contrasts of $\mathrm{V}$ and especially $\mathrm{S}$ were much larger between than within study areas. Cohort exposures more than four times the interquartile range above the 75th percentile occurred (Figs. 1 and 2), but the maximum value was never an isolated single high value. Correlations between estimated elemental concentrations and total mass concentrations in the same size fractions $\left(\mathrm{PM}_{2.5}\right.$ or $\left.\mathrm{PM}_{10}\right)$ were modest on average $(0.5<\mathrm{r}<0.7)$ for traffic tracers (e.g. $\mathrm{Cu}, \mathrm{Fe}$ and $\mathrm{Zn}$ ) and for elements which made up a relatively large fraction of PM (e.g. K, S, Si) and were lower $(0.2<\mathrm{r}$ $<0.5$ ) for $\mathrm{V}$ and $\mathrm{Ni}$ (see Table D.1 in Appendix D). Correlation differed substantially across study areas for all the elements. In total, the eight elements contributed a median of $8.81 \%$ (min-max: $1.89 \%-12.71 \%$ ) and $10.19 \%$ ( $\min -\max : 3.94 \%-18.34 \%$ ) in the same size fraction of the total $\mathrm{PM}_{2.5}$ and $\mathrm{PM}_{10}$ mass respectively within the 19 cohorts, with largest proportion for $\mathrm{S}\left(6.30 \%\right.$ in $\mathrm{PM}_{2.5}, 3.72 \%$ in $\left.\mathrm{PM}_{10}\right)$ and smallest proportion for $\mathrm{V}\left(0.02 \%\right.$ in $\mathrm{PM}_{2.5}, 0.01 \%$ in $\left.\mathrm{PM}_{10}\right)$. Less than $10 \%$ of the addresses in each cohort have been range-truncated for corresponding predictor variables.

\subsection{Main results}

We found no consistent associations between any of the elemental constituents of $\mathrm{PM}_{2.5}$ or $\mathrm{PM}_{10}$ and CVD mortality in the main model (Model 3 in Table 3 ) based on combined analyses of 19 cohorts. Most of the combined HRs were close to unity for PM constituents, with exception of $\mathrm{S}$ in both $\mathrm{PM}_{2.5}$ and $\mathrm{PM}_{10}$ and $\mathrm{PM}_{2.5} \mathrm{Si}$. HR for $\mathrm{PM}_{2.5}$ Si was 1.17 (95\% CI: 0.93-1.47) per $100 \mathrm{ng} / \mathrm{m}^{3}$ and for $\mathrm{S}$ in $\mathrm{PM}_{2.5}$ and $\mathrm{PM}_{10}$ the HRs were 1.08 (95\% CI: 0.95-1.22) and 1.09 (95\% CI: 0.90-1.32) per $200 \mathrm{ng} / \mathrm{m}^{3}$ respectively. The crude adjustment models (Model 1 with adjustment only for calendar year and gender in Table 3 ) showed highest HRs and widest confidence intervals. HRs were above 1, with the association for $\mathrm{S}$ in $\mathrm{PM}_{2.5}$ being statistically significant. The HRs were reduced to unity with decreasing confidence interval after adjustment for especially individual level confounders (Model 2 in Table 3) and area-level socio-economic status variables (Model 3 in Table 3). Significant positive associations of some elements were observed in a few cohorts with CVD mortality individually such as the Dutch EPIC-PROSPECT cohort $\left(\mathrm{PM}_{2.5} \mathrm{Si}, \mathrm{Zn}\right.$ and $\left.\mathrm{PM}_{10} \mathrm{~S}\right)$, and the German SALIA $\left(\mathrm{PM}_{2.5} \mathrm{Si}\right.$ and $\left.\mathrm{PM}_{10} \mathrm{Si}, \mathrm{K}, \mathrm{Zn}\right)$ and KORA $\left(\mathrm{PM}_{2.5} \mathrm{Fe}, \mathrm{Si}, \mathrm{Zn}\right.$ and $\mathrm{PM}_{10} \mathrm{Cu}, \mathrm{Fe}, \mathrm{Si}, \mathrm{S}$ ) cohorts (Figs. 3 and 4).
Heterogeneity between the results of individual cohorts varied substantially across constituents $\left(\mathrm{I}^{2}: 0 \%-58 \%\right)$ and was generally larger for the elemental constituents than for PM mass (Table 3). Most $\mathrm{I}^{2}$ values indicated low $(<25 \%)$ to moderate $(<50 \%)$ heterogeneity (Higgins and Thompson, 2002). HRs using random effects (default method, Figs. 3 and 4) and fixed effects were similar.

\subsection{Sensitivity analyses}

Additional adjustments for hypertension and physical activity, diabetes and cholesterol, and noise did not change the main results of the combined HRs (Tables E.1-E.4 in Appendix E). Using two-pollutant models adjusting for $\mathrm{NO}_{2}$, NOx or PM metrics respectively, while restricting analyses to cohorts with correlations of the two pollutants lower than 0.7 did not change the HRs compared to the single pollutant models in the same cohorts (Figs. E.1-E.2 in Appendix E).

Restricting the meta-analyses to cohorts for which the exposure model had LOOCV $\mathrm{R}^{2} \mathrm{~s}$ of at least 0.5 resulted in removal of many cohorts for estimates of $\mathrm{K}, \mathrm{Ni}, \mathrm{S}$ and $\mathrm{V}$ in $\mathrm{PM}_{2.5}$. No significant difference was observed between cohorts with LOOCV $\mathrm{R}^{2}$ higher and lower than 0.5. No association was found after this restriction (Table E.5 in Appendix E). Restricting analyses to cohorts with port and industrial predictor variables in the LUR models for trace markers of $\mathrm{PM}_{10} \mathrm{~V}$ and $\mathrm{Ni}$ (DCH, EPIC-MORGEN, SNAC-K, SALT, 60 y olds, SDPP, EPIC-Athens for both $\mathrm{V}$ and $\mathrm{Ni}$ and SALIA for $\mathrm{V}$, SIDRIA/EPIC-Turin for Ni), we found slightly elevated but not significant associations with CVD mortality (V 1.04, 95\% CI: 0.90-1.21 per $3 \mathrm{ng} / \mathrm{m}^{3}$; Ni 1.07, 95\% Cl: 0.80-1.42 per $\left.2 \mathrm{ng} / \mathrm{m}^{3}\right)$. Stratified analyses showed inconsistent differences of HRs among regions of Europe but generally no association was identified for any of the elemental constituents on CVD mortality (Table E.6 in Appendix E). The effect estimates remained insignificant when excluding the influential (weight $>50 \%$ ) VHM\&PP cohort for $\mathrm{K}$ and $\mathrm{S}$ in $\mathrm{PM}_{2.5}$. HRs were 0.99 (95\% CI: 0.86-1.14) and 1.19 (95\% CI: 0.97-1.44) for K and $\mathrm{S}$ respectively without the VHM\&PP cohort.

\section{Discussion}

This study found no statistically significant associations between a comprehensive set of elemental constituents of PM and overall cardiovascular mortality based on 19 European cohorts. Most of the combined hazard ratios were close to unity, with exception for $\mathrm{PM}_{2.5}$ Si and $\mathrm{S}$ in $\mathrm{PM}_{2.5}$ and $\mathrm{PM}_{10}$.

The strengths of this study include: 1) the use of a large population of 19 study cohorts from 12 countries with a relatively long follow-up history and with detailed individual-level information; 2) the use of a comprehensive set of potential confounders including smoking status and intensity, area-level SES and other important variables, which are at least comparable to those used in previous studies e.g. the large U.S. ACS study (Pope et al., 2002); 3) the implementation of standardized Land Use Regression models for many of the measured PM elemental constituents for fine scale predictions (De Hoogh et al., 2013; Wang et al., 2013a, b); few previous European and American studies assessed PM constituents by modeling but assigned individual exposures from the nearest monitoring stations(Ostro et al., 2010).

Our study provides more insight to the findings of Beelen et al. (accepted for publication) who reported no significant associations between any of the pollutants $\mathrm{NO}_{2}, \mathrm{NOx}, \mathrm{PM}_{2.5}, \mathrm{PM}_{10}$ and $\mathrm{PM}_{2.5}$ absorbance and CVD mortality within the ESCAPE project. The median correlations between elemental constituents and PM mass concentrations were low to modest at the cohort addresses, in agreement with the previously reported moderate correlation of modeled exposures at monitoring sites not used for modeling (De Hoogh et al., 2013). This suggests that mortality effects from elemental constituents could be different from the particle mass mortality effects.

However, we did not identify any significant associations between CVD mortality and PM elemental constituents across the 19 cohorts. 
Most of the hazard ratios were close to unity for PM constituents. In the single published study evaluating long-term exposure to $\mathrm{PM}_{2.5}$ constituents, the California Teachers Study (CTS), significant HRs for cardiopulmonary mortality were found for mass, sulfate, nitrate and $\mathrm{Si}$, whereas HRs were elevated but non-significant for $\mathrm{K}$, Fe and Zn (Ostro et al., 2011). $\mathrm{Ni}, \mathrm{V}$ and $\mathrm{Cu}$ were not reported. In the CTS study, relatively high correlations between $\mathrm{PM}_{2.5}$ and constituents $(0.67[\mathrm{~K}]<\mathrm{r}<0.84[\mathrm{Zn}])$ were found, so some of the reported associations may be a $\mathrm{PM}_{2.5}$ effect. Compared to the CTS study (Ostro et al., 2010, 2011), we moreover attributed within-area exposures of constituents to individual cohort members as substantial spatial variability has been identified within each study areas for most of the elements (De Hoogh et al., 2013). In addition, the CTS cohort has relatively larger exposure contrasts (between counties) to the elements (Fe, K, Si and $\mathrm{Zn}$ ) and on average a slightly older population (53.4 years in the CTS compared to a cohort size-weighted average 50.5 years in our study) which may increase susceptibility to air pollution exposure compared to the cohorts in our study.

Although elemental effects on cardiovascular disease have been examined in a few short-term studies, results varied substantially across studies (Ito et al., 2011; Zhou et al., 2011). In countrywide studies, effects estimates were significantly increased only for $\mathrm{V}$ and $\mathrm{Ni}$ in the United States (Bell et al., 2009; Lippmann et al., 2006). Some large scale, short-term studies in the U.S. showed no association between CVD outcomes and Cu, Fe and Zn (Bell et al., 2009; Lippmann et al., 2006) in line with our study results whereas four other studies found associations with $\mathrm{Cu}$, Fe or $\mathrm{Zn}$ in smaller regions (Ostro et al., 2007; Sarnat et al., 2008; Valdes et al., 2012; Zhou et al., 2011).

We found elevated HRs for $\mathrm{PM}_{2.5}$ Si and $\mathrm{S}$ in $\mathrm{PM}_{2.5}$ and $\mathrm{PM}_{10}$ though not statistically significant. Chance may be an explanation for the elevated HRs, though the results are consistent with the CTS study on long-term exposures. For $\mathrm{S}$ the observation of elevated HRs in both the $\mathrm{PM}_{2.5}$ and $\mathrm{PM}_{10}$ fraction is also suggestive for an association. For $\mathrm{Si}$, it is inconsistent that only an elevated $\mathrm{HR}$ in the $\mathrm{PM}_{2.5}$ fraction was found, whereas $\mathrm{Si}$ is much higher in the $\mathrm{PM}_{10}$. Mineral and road dust are the primary sources of Si (Viana et al., 2008). The cardio-toxicity effects of $\mathrm{PM}_{2.5}$ Si have been presented in some studies (Ito et al., 2011; Valdes et al., 2012; Zhou et al., 2011) but not in others (Bell et al., 2009; Lippmann et al., 2006; Ostro et al., 2007; Sarnat et al., 2008). S is part of vehicle exhausts but is mostly determined by secondary aerosol formation. In this study, the spatial variation of S was mostly explained by various traffic, land use (green) and residential density variables (De Hoogh et al., 2013) and thus $S$ represents a combination of urban sources including traffic emissions and possibly residential oil combustion.

The non-significant associations found in our study for the eight a priori selected elements could be due to a combination of exposure measurement error, exposure contrast, studied outcomes, the application of a current LUR to assess historic exposures or a true absence of an effect. First, it is unlikely that limited validity of the LUR models fully explains the lack of associations. The LUR models explained fairly large concentration contrasts of (especially the traffic-related) constituents in most of the study areas though poor predictions for several $\mathrm{PM}_{2.5}$ constituents (e.g. K, $\mathrm{Ni}, \mathrm{S}$ and $\mathrm{V}$ ) were found in several study areas. This is due to lack of GIS predictor variables for specific sources, for instance biomass burning for $\mathrm{K}$ or absence of the major source e.g. for $\mathrm{Ni}$ and $\mathrm{V}$ in several areas (De Hoogh et al., 2013). Moreover, our site selection was designed for estimating especially the health effects on traffic pollution which may restrict the power to detect other emission sources. We restricted the analyses to the cohorts with reliable concentration estimates and did not find significant associations with CVD mortality in these cohorts. In our study, V and $\mathrm{Ni}$ were mainly explained by a combination of industry, port, residential density and traffic variables, in agreement with previous European source apportionment studies which suggested fuel (and its derivates e.g. shipping emission), residential oil combustion and industrial emissions (Viana et al., 2008). When we restricted analyses to the cohorts with port and industry variables for $\mathrm{PM}_{10} \mathrm{~V}$ and Ni respectively, effect estimates were larger but far from statistically significant. Although these
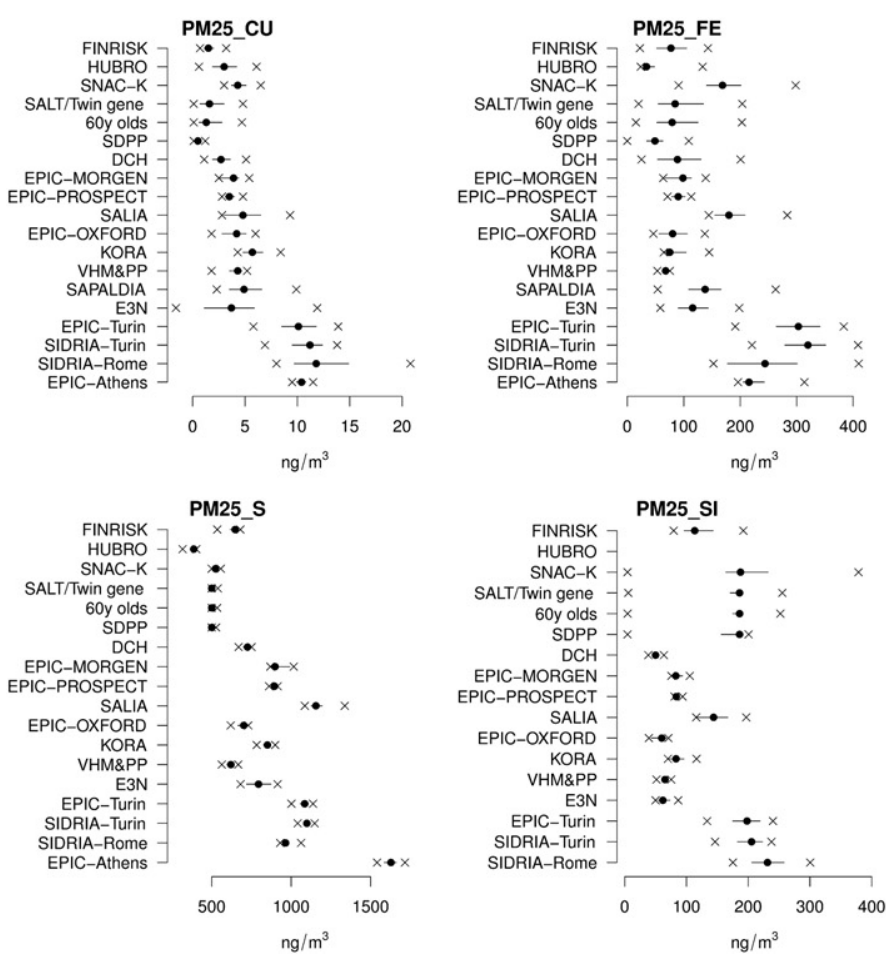
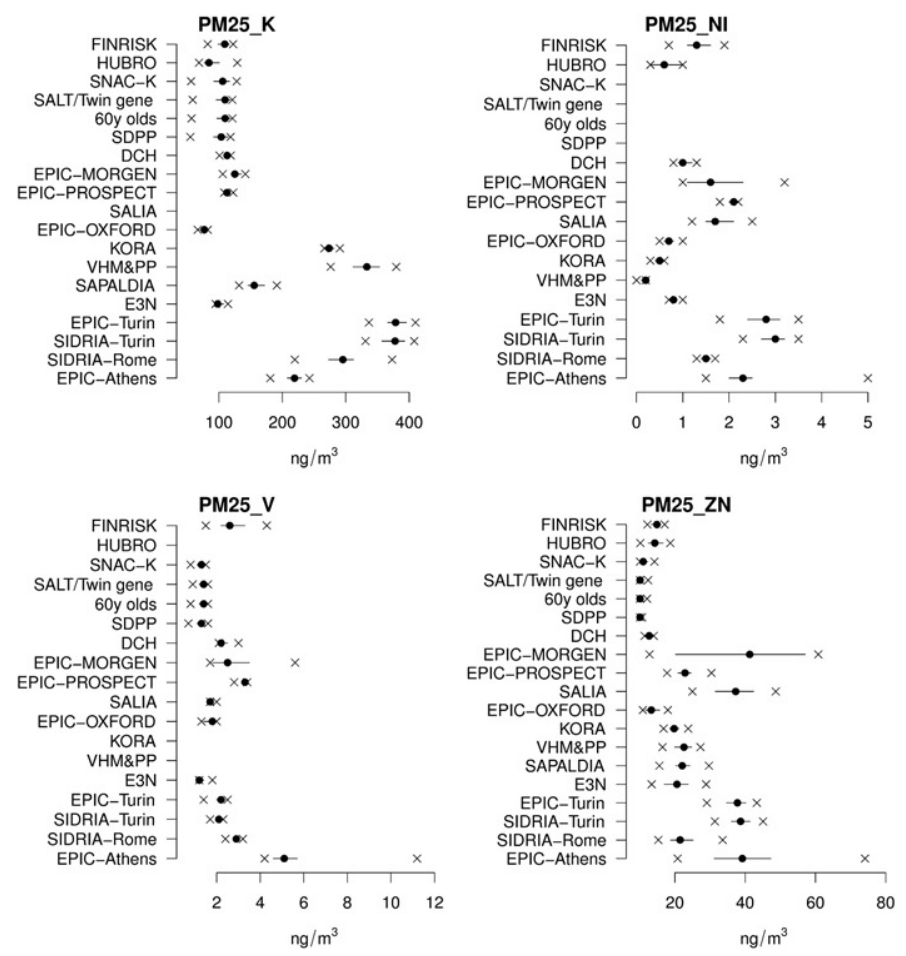

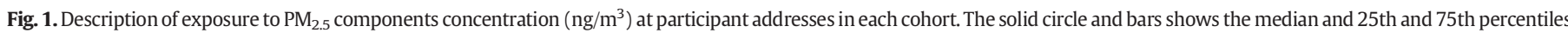
of elemental constituents of $\mathrm{PM}_{2.5}$; the $\mathrm{x}$ shows the 5 th and 95th percentile values. 

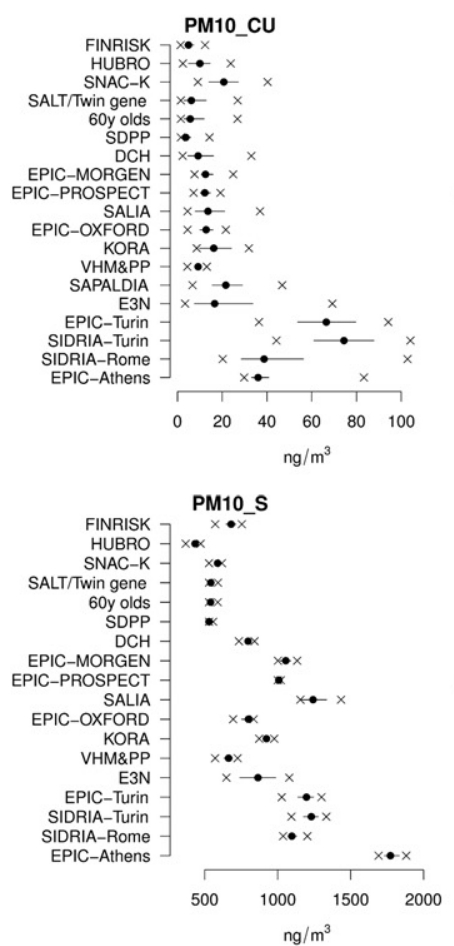
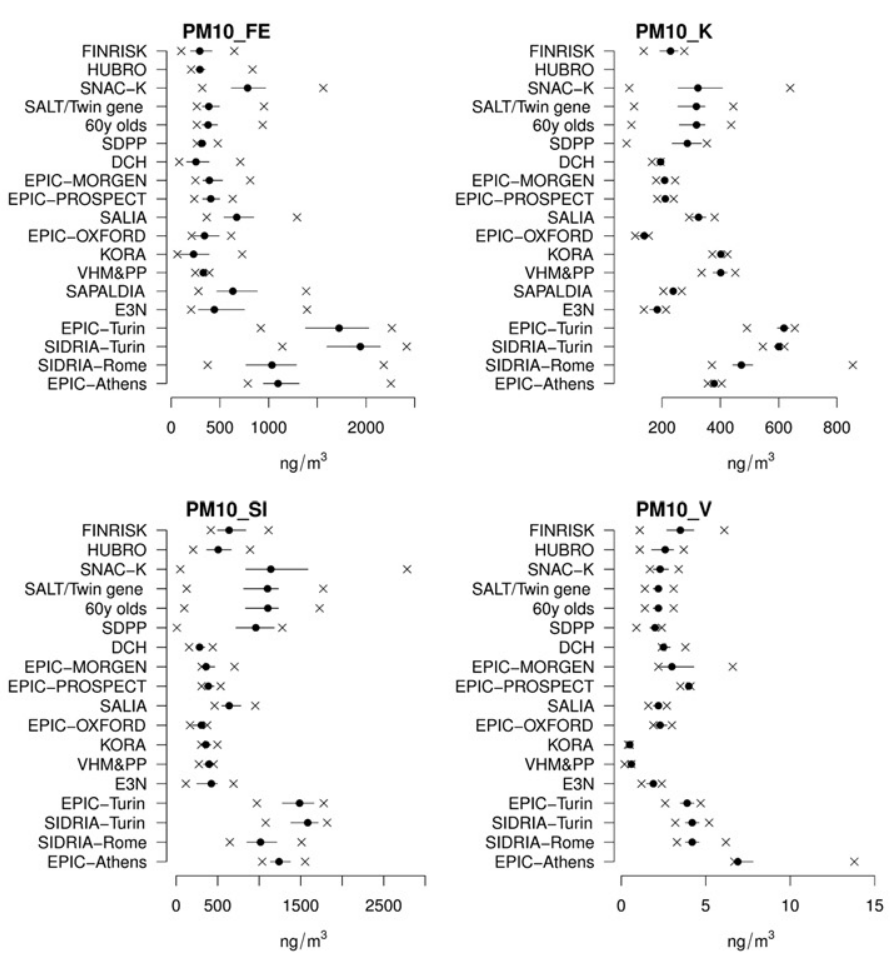
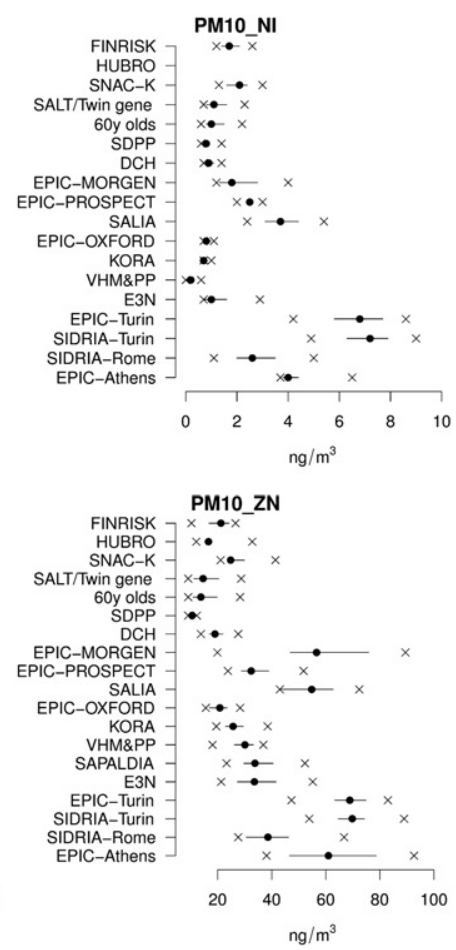

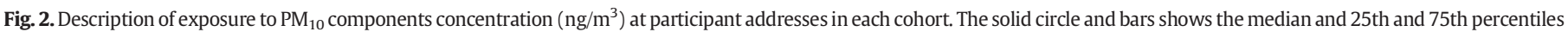
of elemental constituents of $\mathrm{PM}_{10}$; the $\mathrm{x}$ shows the 5 th and 95 th percentile values.

analyses suggest that limited validity of LUR models does not fully explain the lack of associations, we cannot exclude the possibility that our effect estimates have been underestimated (Basagaña et al., 2013).

Second, limited contrast in exposure may have contributed to the non-significant findings for some elements. Limited contrast was found for particularly sulfur related to the relatively small size of our study areas, e.g. in comparison with CTS study which had 10 -fold larger S contrast (Ostro et al., 2010). We did find large within cohort contrast for especially $\mathrm{Cu}, \mathrm{Fe}$ and $\mathrm{Zn}$. The variation in $\mathrm{Cu}$, Fe and $\mathrm{Zn}$ was explained by traffic related variables (e.g. traffic intensity and road length) in many cohort areas. $\mathrm{Cu}, \mathrm{Fe}$ and $\mathrm{Zn}$ are recognized as trace markers of traffic from a combination of brake/tire-wear, vehicle exhausts and road dusts (Viana et al., 2008).

Third, the general explanations for a lack of association between CVD mortality and PM offered by Beelen et al. (accepted for publication) may apply. This included better medication and medical treatment and

Table 3

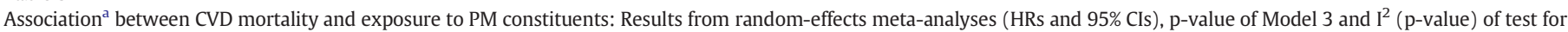
heterogeneity of effect estimates between cohorts (using main confounder Models 1, 2 and 3).

\begin{tabular}{|c|c|c|c|c|c|c|c|c|}
\hline Cohorts & Exposure & & Model $1^{b}$ & Model $2^{b}$ & Model $3^{b}$ & $\mathrm{Pm}^{\mathrm{C}}$ & $P_{\text {het }}$ & $\mathrm{I}^{2}$ \\
\hline 19 & $\mathrm{Cu}$ & $\mathrm{PM}_{2.5}$ & $1.03(0.88-1.21)$ & $0.96(0.83-1.11)$ & $0.90(0.77-1.07)$ & 0.26 & 0.03 & 42.77 \\
\hline 19 & & $\mathrm{PM}_{10}$ & $1.00(0.89-1.13)$ & $0.95(0.84-1.08)$ & $0.93(0.82-1.06)$ & 0.29 & 0.01 & 48.83 \\
\hline 19 & $\mathrm{Fe}$ & $\mathrm{PM}_{2.5}$ & $1.07(0.94-1.23)$ & $1.01(0.89-1.15)$ & $0.99(0.87-1.11)$ & 0.82 & 0.09 & 31.93 \\
\hline 19 & & $\mathrm{PM}_{10}$ & $1.03(0.91-1.16)$ & $0.98(0.86-1.12)$ & $0.96(0.84-1.09)$ & 0.55 & 0.00 & 53.49 \\
\hline 18 & K & $\mathrm{PM}_{2.5}$ & $0.98(0.94-1.02)$ & $0.98(0.94-1.02)$ & $0.98(0.94-1.02)$ & 0.37 & 0.62 & 0.00 \\
\hline 18 & & $\mathrm{PM}_{10}$ & $1.02(0.94-1.11)$ & $1.01(0.94-1.07)$ & $1.00(0.93-1.08)$ & 0.92 & 0.27 & 15.03 \\
\hline 14 & $\mathrm{Ni}$ & $\mathrm{PM}_{2.5}$ & $1.05(0.86-1.28)$ & $0.98(0.78-1.24)$ & $0.97(0.78-1.21)$ & 0.80 & 0.02 & 48.63 \\
\hline 17 & & $\mathrm{PM}_{10}$ & $1.12(0.93-1.36)$ & $1.02(0.87-1.19)$ & $1.01(0.88-1.16)$ & 0.90 & 0.35 & 9.11 \\
\hline 18 & $\mathrm{~S}$ & $\mathrm{PM}_{2.5}$ & $1.27(1.01-1.61)$ & $1.09(0.97-1.24)$ & $1.08(0.95-1.22)$ & 0.25 & 0.68 & 0.00 \\
\hline 18 & & $\mathrm{PM}_{10}$ & $1.21(0.97-1.50)$ & $1.11(0.92-1.33)$ & $1.09(0.90-1.32)$ & 0.40 & 0.06 & 36.46 \\
\hline 16 & $\mathrm{Si}$ & $\mathrm{PM}_{2.5}$ & $1.28(0.98-1.66)$ & $1.21(0.94-1.54)$ & $1.17(0.93-1.47)$ & 0.21 & 0.01 & 52.04 \\
\hline 18 & & $\mathrm{PM}_{10}$ & $1.09(0.93-1.28)$ & $1.03(0.91-1.17)$ & $1.01(0.90-1.13)$ & 0.85 & 0.08 & 33.87 \\
\hline 15 & $\mathrm{~V}$ & $\mathrm{PM}_{2.5}$ & $1.14(0.86-1.52)$ & $1.00(0.79-1.27)$ & $1.00(0.80-1.24)$ & 0.99 & 0.19 & 24.10 \\
\hline 18 & & $\mathrm{PM}_{10}$ & $1.04(0.83-1.30)$ & $1.01(0.86-1.18)$ & $1.00(0.85-1.17)$ & 0.99 & 0.32 & 11.10 \\
\hline 19 & $\mathrm{Zn}$ & $\mathrm{PM}_{2.5}$ & $1.08(0.90-1.29)$ & $1.06(0.90-1.25)$ & $1.04(0.88-1.24)$ & 0.63 & 0.00 & 58.59 \\
\hline 19 & & $\mathrm{PM}_{10}$ & $1.06(0.91-1.24)$ & $1.03(0.90-1.19)$ & $1.00(0.86-1.16)$ & 0.99 & 0.00 & 57.47 \\
\hline 19 & Total & $\mathrm{PM}_{2.5}{ }^{\mathrm{d}}$ & $1.18(1.00-1.38)$ & $1.04(0.93-1.17)$ & $0.99(0.91-1.08)$ & 0.80 & 0.80 & 0.00 \\
\hline 19 & & $\mathrm{PM}_{10}{ }^{\mathrm{d}}$ & $1.10(0.95-1.26)$ & $1.04(0.92-1.16)$ & $1.02(0.91-1.14)$ & 0.69 & 0.69 & 20.20 \\
\hline
\end{tabular}

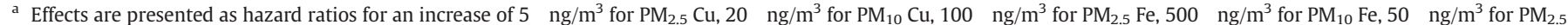

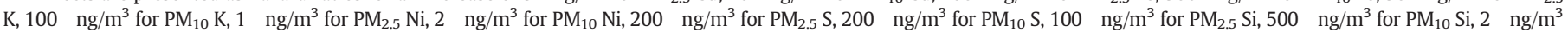
for $\mathrm{PM}_{2.5} \mathrm{~V}, 3 \mathrm{ng} / \mathrm{m}^{3}$ for $\mathrm{PM}_{10} \mathrm{~V}, 10 \mathrm{ng} / \mathrm{m}^{3}$ for $\mathrm{PM}_{25} \mathrm{Zn}$, and $20 \mathrm{ng} / \mathrm{m}^{3}$ for $\mathrm{PM}_{10} \mathrm{Zn}$.

b Model 1: adjusted for gender and calendar time; Model 2: as in Model 1 also adjusting for smoking status, smoking intensity, smoking duration, environmental tobacco smoke, fruit

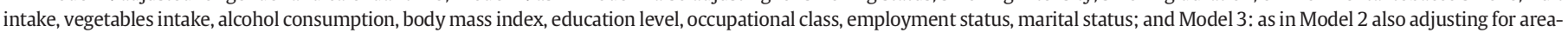
level socio-economic status.

c Pm: p-value of HR from meta-analysis in Model 3.

d Association between CVD mortality and $\mathrm{PM}_{2.5}, \mathrm{PM}_{10}$ mass concentrations reported by Beelen et al. (accepted for publication). 

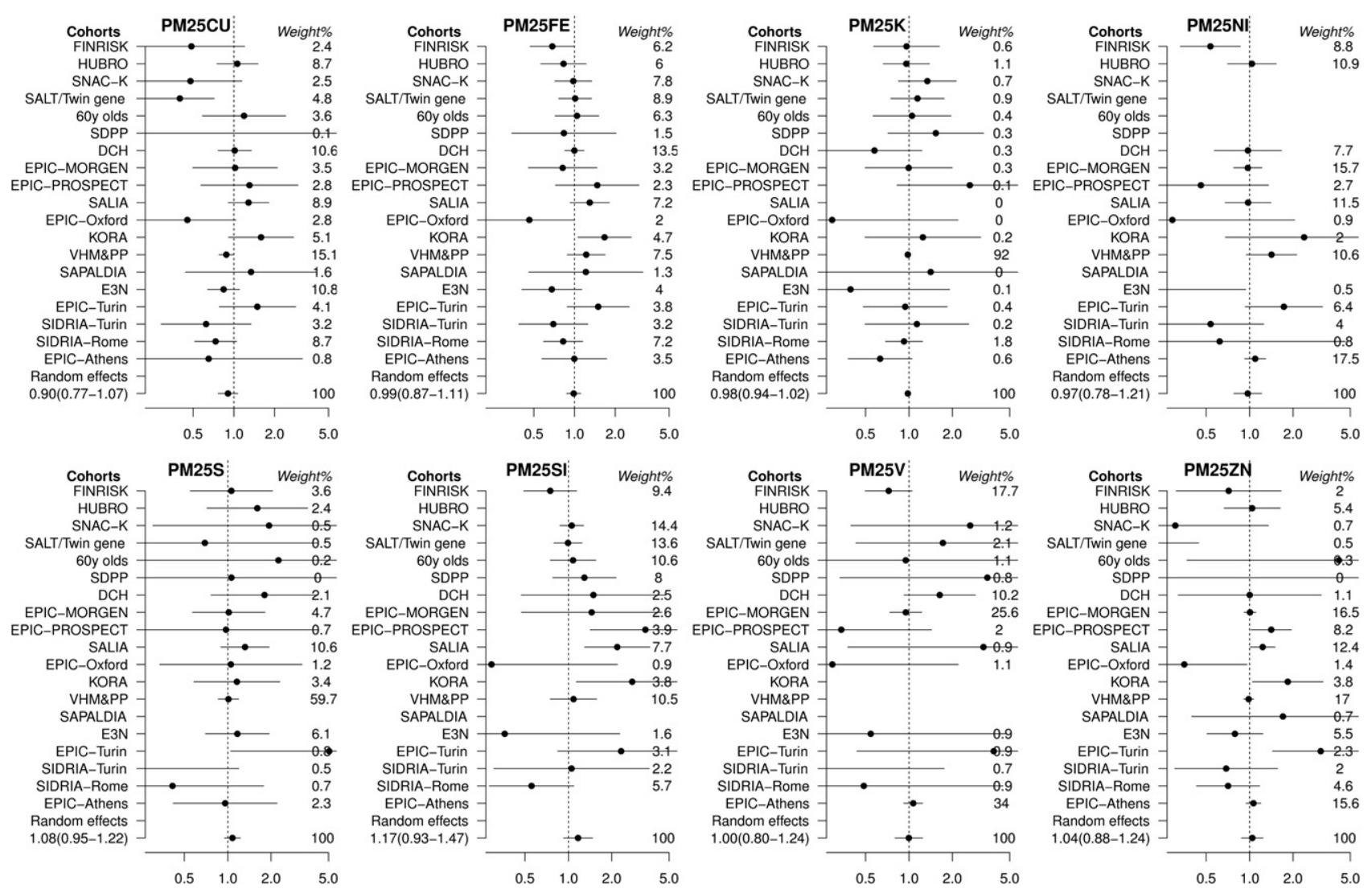

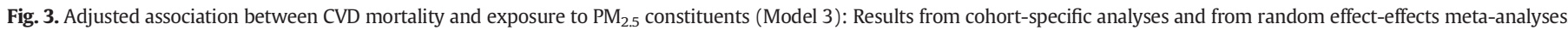

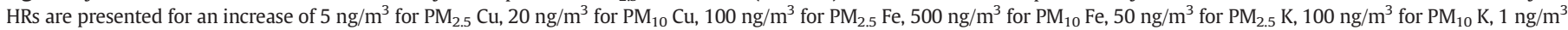

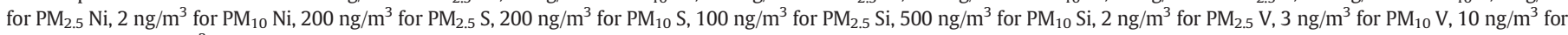
$\mathrm{PM}_{2.5} \mathrm{Zn}$, and $20 \mathrm{ng} / \mathrm{m}^{3}$ for $\mathrm{PM}_{10} \mathrm{Zn}$.

reduced smoking, resulting in a lower fatality rate of cardiovascular events (Nichols et al., 2013). We could not evaluate non-fatal events as our study was based on mortality registries. We only evaluated overall cardiovascular mortality and did not evaluate more specific cardiovascular causes such as ischemic heart disease or stroke. This choice was made to limit the chance of false positive findings and no significant associations between $\mathrm{PM}_{2.5}$ and these more specific disease categories were found. We selected overall CVD mortality because we could evaluate the largest number of cases and were concerned of differences in coding across countries especially when evaluating more specific causes.

Fourth, a main limitation in our study is that the LUR models used for exposure assessment were based on air pollution measurements in the period 2008-2011 while cohort studies included in ESCAPE started in the past (1985-2007 with most studies starting in the mid-90s). Four recent studies in The Netherlands (Eeftens et al., 2011), Great Britain(Gulliver et al., 2013), Rome (Cesaroni et al., 2012), and Vancouver (Wang et al., 2013a, 2013b) have shown that for periods up to 10 years spatial air pollution contrasts of $\mathrm{NO}_{2}$ often remained the same. This indicates that the LUR models based on current $\mathrm{NO}_{2}$ data are able to predict historical exposure well. This finding may be applicable to trafficrelated constituents such as $\mathrm{Cu}, \mathrm{Fe}$ and $\mathrm{Zn}$ whereas there is no quantitative evidence for the other constituents which derive from other sources (e.g. biomass burning, industrial emissions).

We did not consider seasonal exposures, as our main interest was in evaluating long-term exposure represented by annual averages and we had only one sample per season available to develop LUR models (De Hoogh et al., 2013). We did not evaluate organic components of PM. In our previous study (Beelen et al., accepted for publication) we did show that $\mathrm{PM}_{2.5}$ absorbance (a surrogate for elemental carbon) was also not associated with CVD mortality. We did not have fine scale ozone data available. Most of our study areas were relatively small and ozone formation is slow, so we expected limited spatial variation of ozone except due to scavenging by NO (lower ozone near busy roads). As we therefore anticipated that ozone variation would simply be the opposite of $\mathrm{NO}$ and $\mathrm{NO}_{2}$ variation, we did not additionally measure ozone.

Moreover, higher heterogeneity may in part also be explained by the larger heterogeneity in the LUR model performance seen for constituencies. We did not consider moving in the current analysis, as we did not observe any difference between movers and non-movers in the main analysis (Beelen et al., accepted for publication).

In summary, we did not find statistically significant associations between any of the eight selected elemental constituents of $\mathrm{PM}_{10}$ and $\mathrm{PM}_{2.5}$ and overall cardiovascular mortality in the 19 European cohort studies. Elevated risks though not statistically significant were found for CVD mortality and $\mathrm{PM}_{2.5} \mathrm{Si}$ and $\mathrm{S}$ in $\mathrm{PM}_{2.5}$ and $\mathrm{PM}_{10}$ respectively.

\section{Acknowledgement}

The research leading to these results has received funding from the European Community's Seventh Framework Program (FP7/20072011): ESCAPE 3 (grant agreement number: 211250) and TRANSPHORM (ENV.2009.1.2.2.1). SAPALDIA received support in mortality record linkage from the Swiss National Cohort Study, grant numbers: Periode 1.7.2006-30.6.2011: 108806, Periode 1.7.2011-30.6.2014: 134273. The KORA research platform and the MONICA Augsburg studies were initiated and financed by the Helmholtz Zentrum München, German Research Center for Environmental Health, which is funded by the German Federal Ministry of Education and Research and by the State of Bavaria. We thank Marjan Tewis, Marieke Oldenwening, Marta Cirach, Audrey de Nazelle, Marianne Rutschi, Gregor Fessler, Alwin Muxel, Bernhard Anwander, Paolo Crosignani, Jon Wickmann, Daniela Raffaele, Marco Gilardetti, Thomas Kuhlbusch, Ulrich Quass, 

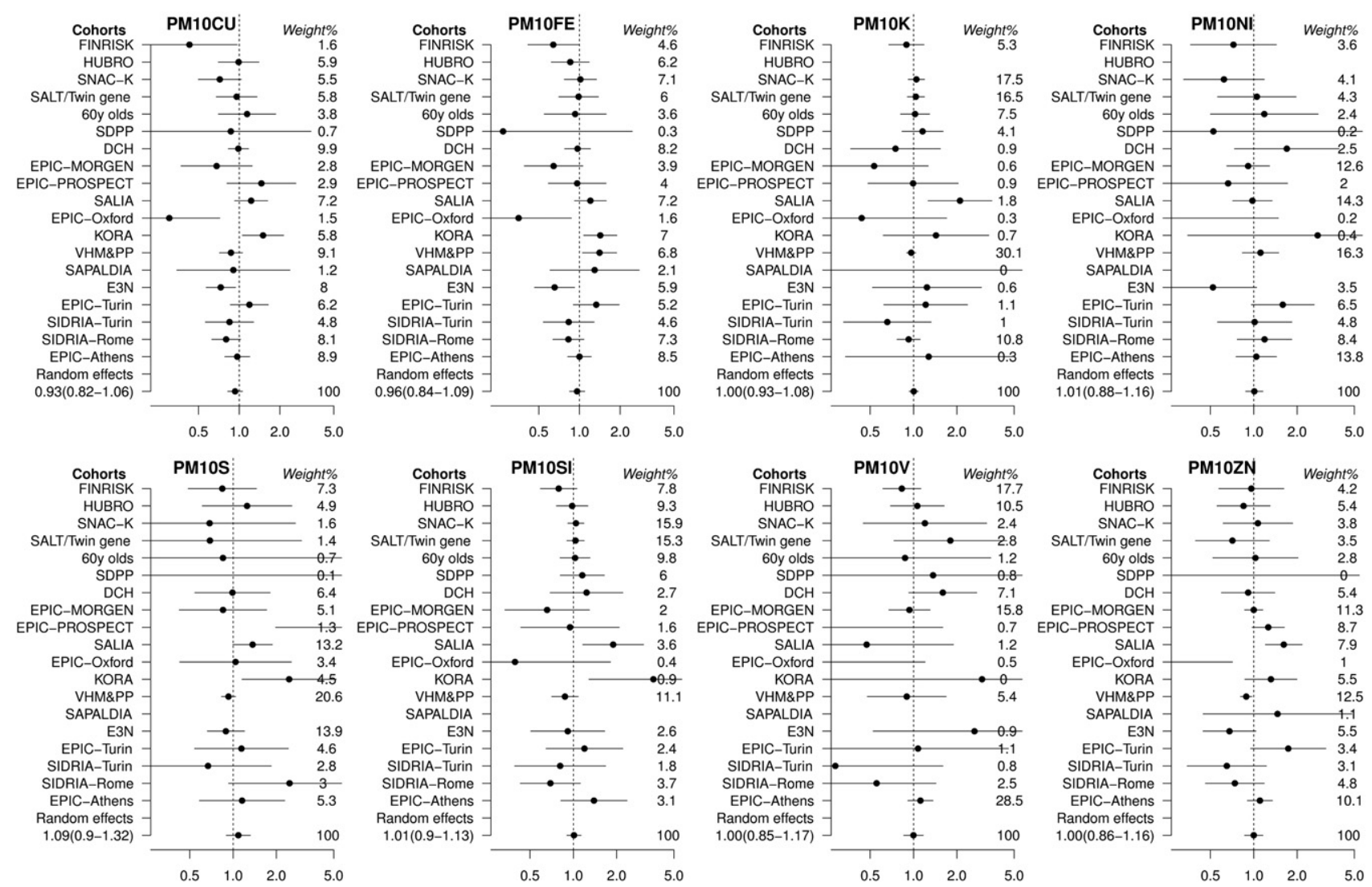

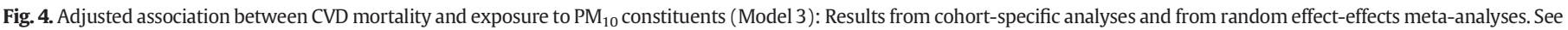
Fig. 3 for increment unit of each element.

Mohammad Vossoughi, Simone Bucci, Patrizio Pasquinelli, Giuseppe Costa, L.-J. Sally Liu, Andrea Kleiner, and Pekka Taimisto, and Arto Pennanen (from the Department of Environmental Health at National Institute for Health and Welfare) for their help with exposure assessment and data management within ESCAPE.

\section{Appendix A. Supplementary data}

Supplementary data to this article can be found online at http://dx. doi.org/10.1016/j.envint.2014.01.026.

\section{References}

Basagaña X, Aguilera I, Rivera M, Agis D, Foraster M, Marrugat J, et al. Measurement error in epidemiologic studies of air pollution based on land-use regression models. Am J Epidemiol 2013;178:1-5

Beelen R, Hoek G, van den Brandt PA, Goldbohm RA, Fischer P, Schouten LJ, et al. Long-term effects of traffic-related air pollution on mortality in a Dutch cohort (NLCS-air study). Environ Health Perspect 2008;116:196-202.

Beelen R, Hoek G, Houthuijs D, van den Brandt PA, Goldbohm RA, Fischer P, et al. The joint association of air pollution and noise from road traffic with cardiovascular mortality in a cohort study. Occup Environ Med 2009;66:243-50.

Beelen R, Stafoggia M, Raaschou-Nielsen O, Andersen ZJ, Xun W, Katsouyanni K, et al. Long-term exposure to air pollution and cardiovascular mortality: an analysis of 22 European cohorts within the ESCAPE project. Epidemiology 2014n. [accepted for publication].

Beelen R, Raaschou-Nielsen O, Stafoggia M, Andersen ZJ, Weinmayr G, Hoffmann B, et al. Effects of long-term exposure to air pollution on natural cause mortality: an analysis of 22 European cohorts within the multi-center ESCAPE project. Lancet 2014 http://dx.doi.org/10.1016/S0140-6736(13)62158-3. [Epub ahead of print]. [in press].

Bell ML, Ebisu K, Peng RD, Samet JM, Dominici F. Hospital admissions and chemica composition of fine particle air pollution. Am J Respir Crit Care Med 2009;179:1115-20.
Brook RD, Rajagopalan S, Pope III CA, Brook JR, Bhatnagar A, Diez-Roux AV, et al. Particulate matter air pollution and cardiovascular disease: an update to the scientific statement from the American Heart Association. Circulation 2010;121:2331-78.

Cao J, Xu H, Xu O, Chen B, Kan H. Fine particulate matter constituents and cardiopulmonary mortality in a heavily polluted Chinese city. Environ Health Perspect 2012;120: 373-8.

Cesaroni G, Porta D, Badaloni C, Stafoggia M, Eeftens M, Meliefste K, et al. Nitrogen dioxide levels estimated from land use regression models several years apart and association with mortality in a large cohort study. Environ Health 2012;11.

Cesaroni G, Badaloni C, Gariazzo C, Stafoggia M, Sozzi R, Davoli M, et al. Long-term exposure to urban air pollution and mortality in a cohort of more than a million adults in Rome. Environ Health Perspect 2013;121:324-31.

De Hoogh K, Wang M, Adam M, Badaloni C, Beelen R, Birk M, et al. Development of land use regression models for particle composition in twenty study areas in Europe. Environ Sci Technol 2013:47:5778-86.

DerSimonian R, Laird N. Meta-analysis in clinical trials. Control Clin Trials 1986;7:177-88.

Dominici F, Peng RD, Barr CD, Bell ML. Protecting human health from air pollution: shifting from a single-pollutant to a multipollutant approach. Epidemiology 2010;21:187-94.

Eeftens M, Beelen R, Fischer P, Brunekreef B, Meliefste K, Hoek G. Stability of measured and modelled spatial contrasts in $\mathrm{NO}_{2}$ over time. Occup Environ Med 2011;68:765-70.

Eeftens M, Tsai MY, Ampe C, Anwander B, Beelen R, Bellander T, et al. Spatial variation of $\mathrm{PM}_{25}, \mathrm{PM}_{10}, \mathrm{PM}_{25}$ absorbance and PM coarse concentrations between and within 20 European study areas and the relationship with $\mathrm{NO}_{2}$ - results of the ESCAPE project. Atmos Environ 2012;62:303-17.

Gerlofs-Nijland ME, Dormans JA, Bloemen HJ, Leseman DL, John A, Boere F, et al. Toxicity of coarse and fine particulate matter from sites with contrasting traffic profiles. Inhal Toxicol 2007;19(13):1055-69.

Gulliver J, de Hoogh K, Hansell A, Vienneau D. Development and back-extrapolation of $\mathrm{NO}_{2}$ land use regression models for historic exposure assessment in Great Britain. Environ Sci Technol 2013;47:7804-11.

Happo MS, Hirvonen MR, Halinen AI, Jalava PI, Pennanen AS, Sillanpaa M, et al. Chemical compositions responsible for inflammation and tissue damage in the mouse lung by coarse and fine particulate samples from contrasting air pollution in Europe. Inhal Toxicol 2008;20(14):1215-31.

Happo MS, Hirvonen MR, Halinen AI, Jalava PI, Pennanen AS, Sillanpaa M, et al. Seasonal variation in chemical composition of size-segregated urban air particles and the inflammatory activity in the mouse lung. Inhal Toxicol 2010;22(1):17-32.

Higgins JP, Thompson SG. Quantifying heterogeneity in a meta-analysis. Stat Med 2002;21: 1539-58. 
Hoek G, Krishnan RM, Beelen R, Peters A, Ostro B, Brunekreef B, et al. Long-term air pollution exposure and cardio-respiratory mortality: a review. Environ Health 2013;12:43.

Ito K, Mathes R, Ross Z, Nadas A, Thurston G, Matte T. Fine particulate matter constituents associated with cardiovascular hospitalizations and mortality in New York City. Environ Health Perspect 2011;119:467-73.

Kelly FJ, Fussell JC. Size, source and chemical composition as determinants of toxicity attributable to ambient particulate matter. Atmos Environ 2012;60:504-26.

Laden F, Schwartz J, Speizer FE, Dockery DW. Reduction in fine particulate air pollution and mortality - extended follow-up of the Harvard six cities study. Am J Respir Crit Care Med 2006;173:667-72.

Lepeule J, Laden F, Dockery D, Schwartz J. Chronic exposure to fine particles and mortality: an extended follow-up of the Harvard six cities study from 1974 to 2009. Environ Health Perspect 2012;120:965-70.

Lippmann M, Ito K, Hwang JS, Maciejczyk P, Chen LC. Cardiovascular effects of nickel in ambient air. Environ Health Perspect 2006;114:1662-9.

Lipsett MJ, Ostro BD, Reynolds P, Goldberg D, Hertz A, Jerrett M, et al. Long-term exposure to air pollution and cardiorespiratory disease in the California teachers study cohort. Am J Respir Crit Care Med 2011;184:828-35.

Nichols M, Townsend N, Scarborough P, Rayner M. Trends in age-specific coronary heart disease mortality in the European Union over three decades: 1980-2009. Eur Heart J 2013. http://dx.doi.org/10.1093/eurheartj/eht159.

Ostro B, Feng WY, Broadwin R, Green S, Lipsett M. The effects of components of fine particulate air pollution on mortality in California: results from Calfine. Environ Health Perspect 2007;115:13-9.

Ostro B, Lipsett M, Reynolds P, Goldberg D, Hertz A, Garcia C, et al. Long-term exposure to constituents of fine particulate air pollution and mortality: results from the California teachers study. Environ Health Perspect 2010;118:363-9.

Ostro B, Reynolds P, Goldberg D, Hertz A, Burnett RT, Shin H, et al. Assessing long-term exposure in the California teachers study. Environ Health Perspect 2011;119:A242-3.
Pope III CA, Burnett RT, Thun MJ, Calle EE, Krewski D, Ito K, et al. Lung cancer, cardiopulmonary mortality, and long-term exposure to fine particulate air pollution. JAMA 2002;287:1132-41.

Puett RC, Hart JE, Suh H, Mittleman M, Laden F. Particulate matter exposures, mortality, and cardiovascular disease in the health professionals follow-up study. Environ Health Perspect 2011;119:1130-5.

Raaschou-Nielsen O, Andersen ZJ, Beelen R, Samoli E, Stafoggia M, Weinmayr G, et al. Air pollution and lung cancer incidence in 17 European cohorts: prospective analyses from the European Study of Cohorts for Air Pollution Effects (ESCAPE). Lancet Oncol 2013;14:813-22.

Sarnat JA, Marmur A, Klein M, Kim E, Russell AG, Sarnat SE, et al. Fine particle sources and cardiorespiratory morbidity: an application of chemical mass balance and factor analytical source-apportionment methods. Environ Health Perspect 2008;116:459-66.

Valdes A, Zanobetti A, Halonen JI, Cifuentes L, Morata D, Schwartz J. Elemental concentrations of ambient particles and cause specific mortality in Santiago, Chile: a time series study. Environ Health 2012;11:82.

Viana M, Kuhlbusch TAJ, Querol X, Alastuey A, Harrison RM, Hopke PK, et al. Source apportionment of particulate matter in Europe: a review of methods and results. J Aerosol Sci 2008;39:827-49.

Wang M, Beelen R, Eeftens M, Meliefste K, Hoek G, Brunekreef B. Systematic evaluation of land use regression models for $\mathrm{NO}_{2}$. Environ Sci Technol 2012;46:4481-9.

Wang M, Beelen R, Basagana X, Becker T, Cesaroni G, de Hoogh K, et al. Evaluation of land use regression models for $\mathrm{NO}_{2}$ and particulate matter in 20 European study areas: the ESCAPE project. Environ Sci Technol 2013a;47:4357-64.

Wang RR, Henderson SB, Sbihi H, Allen RW, Brauer M. Temporal stability of land use regression models for traffic-related air pollution. Atmos Environ 2013b;64:312-9.

Zhou J, Ito K, Lall R, Lippmann M, Thurston G. Time-series analysis of mortality effects of fine particulate matter components in Detroit and Seattle. Environ Health Perspect 2011;119:461-6. 